\title{
Effects of royal lotus petals on antioxidants of bael-rosella mixed herbal drink
}

\author{
*Kamdaeng, O. and Singkaew, K. \\ Department of Food and Nutrition, Faculty of Home Economics Technology, \\ Rajamangala University of Technology Thanyaburi, Pathum Thani, 12110, Thailand
}

\begin{abstract}
Article history:
Received: 23 July 2020

Received in revised form: 26

August 2020

Accepted: 14 October 2020

Available Online: 31 January

2021
\end{abstract}

\section{Keywords:}

Antioxidants,

Royal lotus petals,

Herbal drink,

Bael-rosella

\section{DOI:}

https://doi.org/10.26656/fr.2017.5(1).374

\begin{abstract}
This research aimed to study the quantity of royal lotus petals and the antioxidant activity in the bael-rosella mixed herbal drink. The recipe of the bael-rosella mixed herbal drink included dried bael, dried rosella, sugar and water at 8.55, 0.85, 5.13 and 85.47\%, respectively. The drink was comprised of various amounts of royal lotus petals at 1.25 , $1.5,2.0$ and $2.5 \%$. The results showed that $2.0 \%$ of royal lotus petals in the mixed herbal drink contained $10^{\circ}$ Brix. Regarding the acceptance of the consumers, $2.0 \%$ of the lotus petals in the mixed herbal drink recipe was highly satisfied. The antioxidant activity of dried royal lotus petals in the bael-rosella mixed herbal drink showed the amounts of $\mathrm{DPPH}$, metal chelation $\left(\mathrm{MC}_{50}\right)$ and inhibition of lipid peroxidation $\left(\mathrm{LC}_{50}\right)$ at $0.91 \pm 0.01$ $\mathrm{mg} / \mathrm{mL}, 10.79 \pm 1.76 \mathrm{mg} / \mathrm{mL}$ and $11.96 \pm 1.21 \mathrm{mg} / \mathrm{mL}$, respectively. Hence, the bael-rosella mixed herbal drink added with royal lotus petals can be considered as a healthy herbal drink.
\end{abstract}

\section{Introduction}

Herbal drinks are the juice that made from several parts of plants, such as flowers, leaves, roots, fruits, seeds, grasses and grains. They are known as thirstquenching drinks. Herbal drinks can be drunk hot and cold. Additionally, they are rich in vitamins, minerals, antioxidants, and they contain many healthy substances. Since the trend of healthy eating and exercising is popular in Thailand nowadays, herbal drinks are what people have a hunger for. Therefore, a demand for herbal drinks is increasing gradually with a market value of up to 2,700 million baht and a growth rate of $10-15 \%$ per year (Ministry of Industry Thailand, 2004).

In Thailand, there are many kinds of flowers that provide beautiful colours and fragrances, and some of them are edible. According to the study of Shi et al. (2008), edible flowers contain antioxidants and phenolic substances that can slow down the aging process. It is also perceived as the anti-cancer agent and it prevents Alzheimer's and coronary artery disease. Thus, the consumption of edible flowers can be considered as an alternative option of a healthy lifestyle because these flowers contain the substances that can be identified as "antioxidants".

Huabbangyang (2010) found that red pigments in flowers contain food nutrients and they have a higher antioxidant capacity than that of white flowers. In fact, red flowers have more substances, namely beta-carotene, flavonoid and anthocyanin than white flowers. As a consequence, blooming red lotus, especially harvested in the morning, contains high nutrients and high antioxidant ability.

Lotuses usually bloom around August to December. This kind of flower has many medicinal properties, such as improving heart health, maintaining strength, nourishing strength, nourishing pregnancy, reducing fever, reducing blood sugar, and containing high fibers. Lotus flowers contain alkaloids called nelumbine. Lotus embryos contain lotusine. Lotus pollens contain many flavonoids, such as quercetin, isoquercitrin, luteolin, luteolin glucoside, and alkaloids (Siriruk, 2009). However, royal lotus petals have an astringent taste that comes from tannins. Thus, people usually eat them with other vegetables to reduce the astringent taste. Also, royal lotus petals can be boiled until they give a mild fragrance to make herbal juice. For these reasons, royal lotus petals are added in the bael-rosella mixed herbal drink, which is a popular herbal drink based on the data derived from the consumer survey. Importantly, the colours from royal lotus petals do not change the colour of the drink (Kamdaeng, 2015).

Bael fruit is known as ancient herbal medicine. 
Unripe bael fruit can be brewed and mixed with water. People usually drink it as a remedy for diarrhea, dysentery, and gastritis, and it helps people to have a good appetite. Bael fruit can also be used as a stomachic mixture, carminative, and analeptic. Moreover, it can cure chronic intestinal diseases in children. Ripe bael fruit has sweet and astringent tastes. It can be used as dysentery and phlegm remedy. It is also a carminative and a laxative that can maintain gastric ulcers, so it is suitable for the elderly who often suffer from constipation. Furthermore, it can cure inner heat and thirst, sharp pain in a stomach, chronic dysentery, and reduce blood sugar level (Homhual, 2017).

Rosella's sepals are thick, red, and juicy, and people usually regard this part as a flower. The medicinal properties of rosellas are varied. For example, it can relieve dryness and thirst, strengthen immunity, and prevent common colds. In fact, rosellas contain anthocyanin or the red substance that can be found in the blueberries group. Rosellas can reduce fever and treat gastritis and enteritis. The medicine can be made by grinding dried rosellas into powder. It can be taken 1 tablespoon of the powder and followed by a glass of water. It is suggested that people should drink it 3-4 times a day. It is a remedy that can help to heal stomach ulcers and prevent the occurrence of peptic ulcers.

Based on the information mentioned above, the objective of this research was to compare the effects of fresh and dried royal lotus petals in the bael-rosella mixed herbal drink in relation to the antioxidant activity.

\section{Materials and methods}

\subsection{Raw materials preparation}

\subsubsection{Fresh royal lotus petals}

Fresh royal lotus petals were washed thoroughly and dried. Then, the petals were cut into $1 \times 3 \mathrm{~cm}$ pieces.

\subsubsection{Dried royal lotus petals}

Dried royal lotus petals were washed thoroughly and dried. After that, they were cut into $1 \times 3 \mathrm{~cm}$ pieces, and then they were dried at $60^{\circ} \mathrm{C}$ for $4 \mathrm{hrs}$.

\subsubsection{Bael fruits}

Roast bael fruit was heated until it was fragrant.

\subsection{Bael-rosella mixed herbal drink preparation}

Approximately, $0.8 \%$ of dried rosella, $8.55 \%$ of bael fruit and $5.13 \%$ of sugar were boiled for 30 mins and then filtered.
A total of four concentrations of fresh royal lotus petals at 1.5, 2.0, 2.5 and 3.0\% were used in Bael-rosella mixed herbal drink. Then, another three amounts of dried royal lotus petals at $0.4,0.8$ and $1.25 \%$ were also used in the drink. The data collection was designed by applying the Completely Randomized Design (CRD) to measure the colour of the drink, and the sensory quality testing with the 9-point Hedonic Scaling $(1=$ dislike the most, and $9=$ like the most), with the Randomized Complete Block Design (RCBD). The samples were analyzed in triplicate, and the sensory test was conducted with the consumers. The variance was analyzed by using ANOVA at the $95 \%$ confidence level. The differences were analyzed by using the Duncan's Multiple Range Test.

\subsection{Antioxidant activity}

An analysis of the antioxidant activity of the baelrosella mixed herbal drink added with royal lotus petals was conducted with the free radical scavenging activity using the DPPH method, metal chelation activity and lipid peroxidation activity (Kim et al., 2008; Boonpisuttinant et al., 2014).

\subsubsection{Free radical scavenging activity using the DPPH method}

The samples and vitamin $\mathrm{C}$ at concentrations of 0.01 , $0.1,1,10$ and $100 \% / \mathrm{mL}$. were prepared, and each sample solution of $50 \mu \mathrm{l}$ concentration was mixed with vitamin $\mathrm{C}$ in a 96-well plate. The samples were shaken well to mix the substances and kept in the dark for 30 mins. After that, the microplate reader absorption measurement at $560 \mathrm{~nm}$ wavelength was used to calculate the antioxidant activity (Boonpisuttinant et al., 2014).

\subsubsection{Lipid peroxidation activity}

The samples were prepared with vitamin $\mathrm{E}$ at concentrations of $0.01,0.1,1,10$ and $100 \% / \mathrm{mL}$. Each sample solution of $50 \mu \mathrm{l}$ concentrations was mixed with vitamin $\mathrm{E}$ at the in a 96-well plate. A solution of $1 \mathrm{mg} /$ $\mathrm{mL}$ of linoleic acid emulsion was dissolved in $50 \%$ DMSO of $50 \mu \mathrm{l}$. Then, $1 \mathrm{mg} / \mathrm{mL}$ solution of $\mathrm{NH}_{4} \mathrm{SCN}$ was dissolved in $1 \% \mathrm{HCl}$ of $50 \mu \mathrm{l}$ and shake well. It was then placed in the dark for 60 mins. The microplate reader absorption measurement set at $450 \mathrm{~nm}$ wavelength was used to calculate the inhibition of fat percentage reaction (Boonpisuttinant et al., 2014).

\subsubsection{Metal chelation activity}

The samples were prepared with EDTA at concentrations of $0.01,0.1,1,10$ and $100 \% / \mathrm{mL}$. Each sample solution of $50 \mu \mathrm{L}$ was mixed with EDTA in a 96well plate. Then, ferrozine of $50 \mu \mathrm{L}$ was filled into the 
samples. Concentrated $\mathrm{FeCl} 2$ solution at $1 \mathrm{mg} / \mathrm{mL}$ was then dissolved in $1 \% \mathrm{HCl}$, and then of the mixed solution at the amount of $50 \mu \mathrm{L}$ was shake well. Then, it was kept in the dark for 60 mins. The microplate reader imports light absorption at $560 \mathrm{~nm}$ wavelength was used to calculate the metal chelation (Boonpisuttinant et al., 2014).

\section{Results and discussion}

\subsection{Bael-rosella mixed herbal drink preparation}

According to the study, the bael juice mixed with $0.8 \%$ dried rosella was added with $1.5,2.0,2.5$ and $3.0 \%$ of fresh royal lotus petals. Also, the mixed herbal drink was added with $0.4,0.8$ and $1.25 \%$ of dried royal lotus petals. The results showed that the appropriate amounts of fresh royal lotus petals and dried royal lotus petals were $2.0 \%$ and $0.8 \%$, respectively. The results are presented in Table 1.

Table 1. Recipe of the bael-rosella mixed herbal drink protocol

\begin{tabular}{lcc}
\hline \multirow{2}{*}{ Ingredients } & \multicolumn{2}{c}{ Amounts } \\
\cline { 2 - 3 } & Grams & Percentage \\
\hline Dried bael fruit & 100 & 8.55 \\
Dried rosella & 10 & 0.85 \\
Sugar & 60 & 5.13 \\
Water & 1000 & 85.47 \\
\hline Total & 1170 & 100 \\
\hline
\end{tabular}

Using $2.0 \%$ of fresh lotus petals, the colour measured was $\mathrm{L}=22.9, \mathrm{a}=6.7, \mathrm{~b}=3.3$ and the sweetness was $10 \%$ Brix, which was the right amount to produce a quince herb drink with roselle with fresh lotus petals. The consumers gave the highest overall preference score to this drink amongst the four samples. This bael-rosella mixed herbal drink had a better appearance and beautiful colour. The fragrance, taste and sweetness were modest, and the consumers accepted it as a suitable recipe of fresh royal lotus petals for the baelrosella mixed herbal drink. The results are presented in Table 2 .
Using $0.8 \%$ of dried lotus petals, the colour measured was $\mathrm{L}=22.9, \mathrm{a}=6.7, \mathrm{~b}=3.3$, and the sweetness was $10 \%$, Brix, which was the right amount to produce a quince herbal drink with roselle with dried lotus petals. The consumers gave the most overall preferences amongst the three samples. This bael-rosella mixed herbal drink with dried lotus petals had a better appearance, brightness and beautiful colour. The fragrance, taste and sweetness of the drink appeared to be modest, and it was accepted by the consumers that it was a suitable recipe for the dried royal lotus petals for the bael-rosella mixed herbal drink. The results are presented in Table 3.

Table 3. Statistical analysis of mean scores from the sensory observation of the amounts of dried lotus petals in three recipes of the bael-rosella mixed herbal drink

\begin{tabular}{lccc}
\hline \multirow{2}{*}{$\begin{array}{c}\text { Sensory } \\
\text { characteristics }\end{array}$} & \multicolumn{3}{c}{ Amounts of dried royal lotus petals (\%) } \\
\cline { 2 - 4 } & 0.4 & 0.8 & 1.25 \\
\hline Appearance & $6.05 \pm 0.15^{\mathrm{b}}$ & $7.75 \pm 0.15^{\mathrm{a}}$ & $7.77 \pm 0.15^{\mathrm{a}}$ \\
Brightness & $6.37 \pm 0.17^{\mathrm{b}}$ & $7.45 \pm 0.17^{\mathrm{a}}$ & $7.88 \pm 0.17^{\mathrm{a}}$ \\
Colour & $6.27 \pm 0.17^{\mathrm{b}}$ & $7.45 \pm 0.17^{\mathrm{a}}$ & $7.45 \pm 0.17^{\mathrm{a}}$ \\
Smell & $6.77 \pm 0.18^{\mathrm{b}}$ & $7.78 \pm 0.18^{\mathrm{a}}$ & $6.85 \pm 0.18^{\mathrm{b}}$ \\
Sweetness & $6.25 \pm 0.21^{\mathrm{b}}$ & $7.08 \pm 0.21^{\mathrm{a}}$ & $6.97 \pm 0.21^{\mathrm{a}}$ \\
Overall liking & $6.50 \pm 0.16^{\mathrm{b}}$ & $7.32 \pm 0.16^{\mathrm{a}}$ & $7.40 \pm 0.16^{\mathrm{a}}$ \\
\hline
\end{tabular}

Values are expressed as mean \pm SD. Values with different superscript within the same row are significantly different $(\mathrm{p} \leq 0.05)$.

\subsection{Antioxidant activity}

Antioxidant activity in the bael-rosella mixed herbal drink added with royal lotus petals was tested by applying the methods of DPPH, Metal chelation activity, and Lipid peroxidation activity. In the first method, the experiment using the free radical scavenging activity showed that the bael-rosella mixed herbal drink added with royal lotus petals with the $100 \% \mathrm{v} / \mathrm{v}$ intensity contained the antioxidant activity three times higher than that of $0.1 \mathrm{mg} / \mathrm{mL}$ of vitamin $\mathrm{C}$ solution. The radical scavenging activity was at $0.37 \pm 0.13 \mathrm{mg} / \mathrm{mL}$ with a statically significant difference $(p<0.05)$, as shown in

Table 2. Statistical analysis of mean scores from the sensory observation of the amounts of fresh royal lotus petals in four recipes of the bael-rosella mixed herbal drink

\begin{tabular}{|c|c|c|c|c|}
\hline \multirow{2}{*}{$\begin{array}{c}\text { Sensory } \\
\text { characteristics }\end{array}$} & \multicolumn{4}{|c|}{ Amounts of fresh royal lotus petals $(\%)$} \\
\hline & 1.5 & 2 & 2.5 & 3 \\
\hline Appearance ${ }^{\mathrm{ns}}$ & $6.85 \pm 0.18$ & $6.98 \pm 0.18$ & $7.13 \pm 0.18$ & $6.70 \pm 0.18$ \\
\hline Brightness & $6.58 \pm 0.18^{\mathrm{b}}$ & $7.22 \pm 0.18^{\mathrm{a}}$ & $6.95 \pm 0.18^{\mathrm{a}}$ & $6.73 \pm 0.18^{\mathrm{a}}$ \\
\hline Colour ${ }^{\text {ns }}$ & $7.20 \pm 0.17$ & $6.78 \pm 0.17$ & $7.13 \pm 0.17$ & $6.98 \pm 0.17$ \\
\hline Smell ${ }^{\mathrm{ns}}$ & $6.62 \pm 0.21$ & $6.72 \pm 0.21$ & $6.68 \pm 0.21$ & $6.78 \pm 0.21$ \\
\hline Sweetness & $7.15 \pm 0.19^{\mathrm{a}}$ & $6.45 \pm 0.19^{\mathrm{b}}$ & $7.02 \pm 0.19^{\mathrm{a}}$ & $6.33 \pm 0.19^{\mathrm{b}}$ \\
\hline Overall liking & $7.13 \pm 0.17^{\mathrm{ab}}$ & $6.75 \pm 0.17^{\mathrm{ab}}$ & $7.28 \pm 0.17^{\mathrm{a}}$ & $6.58 \pm 0.17^{\mathrm{c}}$ \\
\hline
\end{tabular}

Values are expressed as mean \pm SD. Values with different superscript within the same row are significantly different ( $\mathrm{p} \leq 0.05$ ).

${ }^{\mathrm{ns}}$ Values within the same row are not significantly different $(\mathrm{p}>0.05)$. 
Table 4. Results of the antioxidant ability in the bael-rosella mixed herbal drink added with royal lotus petals

\begin{tabular}{lccc}
\hline \multicolumn{1}{c}{ Extraction } & \begin{tabular}{c} 
Antioxidant \\
\cline { 3 - 4 }
\end{tabular} & $(\mathrm{mg} / \mathrm{mL})$ & $\begin{array}{c}\text { Metal chelating activity Inhibition of Lipid peroxidation } \\
\left(\mathrm{MC}_{50}\right)(\mathrm{mg} / \mathrm{mL})\end{array}$ \\
\hline The bael-rosella mixed herbal drink & $0.53 \pm 0.01^{\mathrm{c}}$ & $6.96 \pm 0.58^{\mathrm{d}}$ & $2.30 \pm 0.03^{\mathrm{b}}$ \\
The bael-rosella mixed herbal drink with fresh lotus petal & $0.79 \pm 0.01^{\mathrm{a}}$ & $9.44 \pm 1.99^{\mathrm{a}}$ & $2.73 \pm 0.13^{\mathrm{b}}$ \\
The bael-rosella mixed herbal drink with dried lotus petal & $0.91 \pm 0.01^{\mathrm{b}}$ & $10.79 \pm 1.76^{\mathrm{a}}$ & $11.96 \pm 1.21^{\mathrm{a}}$ \\
Vitamin C & $0.37 \pm 0.13^{\mathrm{d}}$ & - & - \\
EDTA & - & $0.93 \pm 0.37^{\mathrm{c}}$ & - \\
Vitamin E & - & - & $0.35 \pm 0.08^{\mathrm{c}}$ \\
\hline
\end{tabular}

Values are expressed as mean $\pm \mathrm{SD}$. Values with different superscript within the same row are significantly different $(\mathrm{p} \leq 0.05)$.

Table 4.

For the next method of Metal chelation activity, the ferrous metal chelating method was used to find the value of $\mathrm{MC}_{50}$. The relationship of metal chelating activity and the concentration $(\mathrm{mg} / \mathrm{mL})$ of the baelrosella mixed herbal drink added with fresh royal lotus petals caused the ability to chelate metal $\mathrm{MC}_{50}$ at $9.44 \pm 1.99 \mathrm{mg} / \mathrm{mL}$, while the ability to chelate metal $\mathrm{MC}_{50}$ of the bael-rosella mixed herbal drink added with dried royal lotus petals was at $10.79 \pm 1.76 \mathrm{mg} / \mathrm{mL}$. The data also revealed that the bael-rosella mixed herbal drink added with fresh brown royal lotus petals had an ability to chelate metal $\mathrm{MC}_{50}$. However, it had less ability than the EDTA solution with a statically significant difference $(\mathrm{p}<0.05)$. The findings were correlated with Wongklang et al. (2014), who studied the antioxidant from ten parts of royal lotus such as petal, stamen, seed, embryo, torus, young leaf, leaf, petal stalk, bud and root. They found that lotus petals have the highest antioxidant ability.

Lastly, the inhibition of lipid peroxidation activity was tested by using the ferric-thiocyanate method to measure the value of $\mathrm{LC}_{50}$. According to the relationship of lipid peroxidation inhibition activity and the concentration $(\mathrm{mg} / \mathrm{mL})$ of the bael-rosella mixed herbal drink added with fresh royal lotus petals, it was found that the ability to inhibit lipid peroxidation $\left(\mathrm{LC}_{50}\right)$ was at $2.73 \pm 0.13 \mathrm{mg} / \mathrm{mL}$. Moreover, the ability to inhibit lipid peroxidation $\left(\mathrm{LC}_{50}\right)$ of the bael-rosella mixed herbal drink added with dried royal lotus petals was at $11.96 \pm 1.21 \mathrm{mg} / \mathrm{mL}$. The aforementioned data showed that both the bael-rosella mixed herbal drink added with fresh royal lotus petals and the bael-rosella mixed herbal drink added with dried royal lotus petals contained the ability to inhibit lipid peroxidation $\left(\mathrm{LC}_{50}\right)$. However, both types of drink had less anti-oxidation activity than vitamin E solution with a statically significant difference $(\mathrm{p}<0.05)$.

Therefore, the bael-rosella mixed herbal drink added with dried royal lotus petals showed the highest antioxidant activity. This is because the lotus petals in the bael-rosella mixed herbal drink had an effect on the anti-oxidation activity.

\section{Conclusion}

The study of the bael-rosella mixed herbal drink that used $2 \%$ of fresh royal lotus petals, or $0.8 \%$ of dried royal lotus petals, which had sweetness $10 \%$ Brix, obtained the most preference from the consumers. The bael-rosella mixed herbal drink used royal lotus petals has a good appearance, brightness and beautiful colour. It also has good fragrance, good taste and sweetness. In addition, the bael-rosella mixed herbal drink added with dried royal lotus petals had been tested, and the results revealed the highest antioxidant activity. Therefore, consumption of the mixed herbal drink with lotus petals should be promoted as healthy products for health lovers.

\section{Conflict of interest}

The authors declare that there is no conflict of interest regarding the publication of this article.

\section{Acknowledgments}

The researchers would like to express our sincere gratitude to Plant Genetic Conservation Project Under The Royal initiative of Her Royal Highness Princess Maha Chakri Sirindhorn and Faculty of Home Economic Technology of Rajamangala University of Thanyaburi, Thailand.

\section{References}

Boonpisuttinant, K., Sodamook U., Ruksiriwanich W. and Winitchai, S. (2014). In vitro anti-melanogenesis and collagen biosynthesis stimulating activities of Star Grass (Hypoxis aurea Lour.) extracts. Asian Journal of Applied Sciences, 2(4), 405-413.

Homhual S. (2017). Cassumunar ginger. Herb database. Faculty of Pharmacy, Ubon Ratchathani University. Retrieved on April 20, 2017 from Thai Crude Drug Website: www.thaicrudedrug.com/main.php?action $=$ viewpage\&pid $=104$ 
Huabbangyang, O., Buanong, M., Wongs-Aree, C., Techavutthiporn, C. and Srilaong, V. (2010). Study of Nutritional and Free Radical Scavenging Activity in Edible Flowers. Agricultural Science Journal, 41 (3/1), 381-384.

Kamdaeng, O. (2015). Herbal mixed drink with royal lotus petals. Thailand: Faculty of Home Economics Technology, Rajamangala University of Technology Thanyaburi, Thesis.

Kim, Y.H., Kim, K.H., Han, C.S., Park, S.H., Yang, H.C., Lee, B.Y., Eom, S.Y., Kim, Y.S., Kim, J.H. and Lee, N.H. (2008). Anti-inflammatory activity of Crinum asiaticum Linne var. japonicum extract and its application as a cosmeceutical ingredient. Journal of cosmetic science, 59(5), 419-430.

Ministry of Industry Thailand. (2004). Research report of the protocol of investment on Herbal Drink Business. Department of Industry Promotion. Thailand, Ministry of Industry.

Shi, J., Gong, J., Liu, J., Wu, X. and Zhang, Y. (2008). Antioxidant Capacity of Extract from Edible Flowers of Prunus mume in China and its Active Components. Food Science and Technology Journal, 42(2), 477-482. https://doi.org/10.1016/ j.lwt.2008.09.008

Siriruk, P. (2009). Lotus Rhizome: Food and Medicine from the underground. Retrieved on February 29, 2009 from GotoKnow website: www.gotoknow.org/ posts $/ 463537$

Wongklang, S., Steinrut, L. and Itharat, A. (2014). Antioxidant Activity of Nelumbo nucifera Gaerth Extract. Agricultural Science Journal, 45(2), 673676. 